\title{
Rhein inhibits lipopolysaccharide-induced intestinal injury during sepsis by blocking the toll-like receptor 4 nuclear factor-kB pathway
}

\author{
KE ZHANG, XIAN FA JIAO, JIN XIU LI and XIAO WEN WANG \\ Department of Critical Care Medicine, Zhengzhou People's Hospital, Zhengzhou, Henan 450053, P.R. China
}

Received August 19, 2014; Accepted April 30, 2015

DOI: $10.3892 / \mathrm{mmr} .2015 .3925$

\begin{abstract}
Sepsis is one of the leading causes of mortality in severe systemic inflammatory syndrome. The endotoxin-induced inflammatory response has been linked to the development of sepsis. Rhein is a lipophilic anthraquinone isolated from Rheum rhabarbarum (rhubarb), which has a protective effect on intestinal damage in vivo. However, the underlying mechanism responsible for the protective effects of rhein remains to be elucidated. In the present study, mice were exposed to $20 \mathrm{mg} / \mathrm{kg}$ lipopolysaccharide (LPS), prior to being treated with either $100 \mathrm{mg} / \mathrm{kg}$ rhein or $0.3 \mathrm{mg} / \mathrm{kg}$ toll-like receptor 4 (TLR4) signaling inhibitor TAK-242. In the rhein-treated mice, the colon length $(\mathrm{cm})$ was extended and colon injury was attenuated. In addition, treatment with rhein significantly decreased the expression levels of the LPS-induced inflammatory cytokines interleukin (IL)-1 $\beta$, IL-6, IL- 8 , and tumor necrosis factor- $\alpha$, in both the plasma and colon tissue. However, mice treated with TAK-242 exhibited increased expression levels of IL-10, as determined by ELISA and western blot analysis. In addition, immunohistochemistry and western blot analyses demonstrated that treatment with rhein was able to reduce TLR4 expression and inhibit nuclear factor- $\mathrm{\kappa B}(\mathrm{NF}-\kappa \mathrm{B})$ phosphorylation in colon tissue. Furthermore, LPS induction was blocked by TAK-242. These results demonstrate that the observed rhein-attenuated inflammatory response during sepsis may be achieved via the TLR4 NF- $\mathrm{kB}$ signaling pathway. In conclusion, the results of the present study provide a novel insight into the protective effects of rhein on LPS-induced intestinal inflammation, and demonstrate that rhein may act as a beneficial therapeutic agent in the treatment of sepsis-induced intestinal damage.
\end{abstract}

Correspondence to: Miss. Ke Zhang, Department of Critical Care Medicine, Zhengzhou People's Hospital, 33 Huanghe Road, Zhengzhou, Henan 450003, P.R. China

E-mail: zhke198011@163.com

Key words: rhein, sepsis, inflammatory response, toll-like receptor 4, colon

\section{Introduction}

Sepsis is a severe systemic inflammatory response associated with infectious disease, which remains a leading cause of mortality in clinical settings (1). Sepsis usually occurs following a severe infection, and may be triggered by numerous pathogenic microorganisms that release various toxins into the bloodstream and tissues (2). It has been suggested that sepsis is caused by an exaggerated inflammatory response, which may develop into septic shock and multiple organ dysfunction syndrome (3). During a severe infection, intestinal barrier dysfunction may lead to ischemia and hypoxia, both of which have an important role in the development of sepsis (4). In addition, emerging evidence suggests that the intestinal tract is not only a target of the inflammatory response, but may also be the starting point for multiple organ dysfunction (5). Bacterial endotoxins induce intestinal barrier dysfunction by regulating the expression levels of various mediators (6).

Toll-like receptor 4 (TLR4) is a member of the sensor protein family, which has been shown to have an important role in the pathogenesis of inflammatory diseases, including sepsis-associated mortality (7). The activation of TLR4 during sepsis may be associated with the stimulation of the lipopolysaccharide (LPS) endotoxin (8). The development of a TLR4 inhibitor that prevents endotoxin and TLR4 interaction may provide a promising therapeutic target for the treatment of sepsis (9).

Rhein (Fig. 1) is a lipophilic anthraquinone isolated from Rheum rhabarbarum (rhubarb) that exhibits a protective effect on platelet-activated and factor-mediated intestinal damage in rat colon (10). The mechanism underlying the protective activity of rhein may be associated with the generation of nitric oxide, ion secretions and chemotaxis, and with the apoptosis of human-derived Caco-2 colorectal cancer cells (11). Notably, rhein has been shown to successfully repair damaged intestinal tight junctions and protect the intestinal barrier, by enhancing the expression of zona occludens-1 and occludin (12). Furthermore, rhein significantly increased the expression of interleukin (IL)-10, and decreased the expression of tumor necrosis factor (TNF)- $\alpha$ (13). However, the mechanism underlying the protective effects of rhein on LPS-induced intestinal barrier dysfunction remains to be elucidated.

The aim of the present study was to investigate the innate resistance of rhein to LPS-induced intestinal toxicity during 
sepsis in a murine model. Furthermore, the inhibition of rhein in the TLR4 NF- $\mathrm{KB}$ signaling pathway was investigated.

\section{Materials and methods}

Chemicals and reagents. LPS (L-2880:B5) was purchased from Sigma-Aldrich (St. Louis, MO, USA). Rhein (purity >98\%) was purchased from the National Institute for the Control of Pharmaceutical and Biological Products (Beijing, China). ELISA kits used to detect the inflammatory cytokines IL-1 $\beta$, IL-6, IL-8, IL-10, and TNF- $\alpha$ were purchased from the Nanjing Jiancheng Bioengineering Institute (Nanjing, China). The antibodies directed against IL-1 $\beta$, IL-6, IL-8, IL-10, TNF- $\alpha$, TLR-4, and $\beta$-actin, as well as the 3,3'-diaminobenzidine (DAB) reagent were purchased from Wuhan Boster Biological Technology,Ltd.(Wuhan, China). The TLR4 inhibitorTAK-242 was purchased from EMD Millipore (Billerica, MA, USA). SDS-PAGE and polyvinylidene fluoride (PVDF) membranes were obtained from Bio-Rad Laboratories, Inc. (Hercules, CA, USA). The Enhanced Chemiluminescence (ECL) Advanced Western Blotting Detection kit was purchased from GE Healthcare Life Sciences (Chalfont, UK). All other reagents used in the present study were purchased from Sigma-Aldrich. Anti-NF- $\mathrm{kB}$ p65 (phospho S536; cat.no. ab28856) and total anti-NF- $\kappa$ B p65 antibody (cat. no. ab16502) were purchased from Abcam Trading (Shanghai) Company Ltd. (Shanghai, China).

Animal experiments. Four-week-old male BALB/c mice, weighing 18-22 g, were provided by Shanghai Laboratory Animals Center Co., Ltd. (Shanghai, China). The mice were maintained in controlled conditions at $25 \pm 1^{\circ} \mathrm{C}$, a relative humidity of $45 \%$ with $12 \mathrm{~h}$ light/dark cycles, and were given ad libitum access to food and water. The mice were randomly assigned to five experimental groups, consisting of a normal control group, an LPS-stimulated model group, a rhein group, a TLR4 inhibitor group and a rhein + TLR4 inhibitor TAK-242 group ( $\mathrm{n}=10$, each group). The mice in each group were orally administered $100 \mathrm{mg} / \mathrm{kg}$ rhein (14), and $0.3 \mathrm{mg} / \mathrm{kg}$ TAK-242 (15) for $1 \mathrm{~h}$ prior to being injected intraperitoneally with $20 \mathrm{mg} / \mathrm{kg}$ LPS (16) for a further $18 \mathrm{~h}$. The mice were subsequently anesthetized with an intraperitoneal injection of $50 \mathrm{mg} / \mathrm{kg}$ pentobarbital (Merck KGaA, Darmstadt, Germany), prior to having their blood samples taken from the retinal vein. The mice were sacrificed under anesthesia with ketamine at $65 \mathrm{mg} / \mathrm{kg}$ and xylazine at $6.5 \mathrm{mg} / \mathrm{kg}^{-1}$, i.p. (Jiancheng Bioengineering Institute) and $1 \mathrm{~cm}$ from the rectum and $1 \mathrm{~cm}$ from the cecum were harvested in order to evaluate the changes in intestinal injury. The length of the colons were measured and recorded. The present study was approved by the Institutional Animal Care and Use Committee of Zhengzhou People's Hospital, (Zhengzhou, China).

Intestinal mucosal pathology. The extent of intestinal mucosal injury was graded following inspection under a microscope (Olympus IX71; Olympus, Tokyo, Japan), according to the standard classification described by Chiu et al (17). Intestinal injury was graded as follows: 0 , normal mucosal villi; 1 , the gap in the epithelium increased, and capillary congestion at the tip of villi was observed; 2 , the gap in the epithelium was expanded with moderate separation of the epithelium and lamina propria; 3 , severe separation of the epithelium and lamina propria with damage to the villus tip; 4, villi were damaged and the capillaries exposed in the lamina propria, an increase in the cellular components of the lamina propria was also observed; and 5, the intrinsic layer was damaged with incomplete bleeding and ulcers.

Immunohistochemistry. Sections of $4 \mu \mathrm{m}$ formalin-fixed, paraffin-embedded colon tissue was cut for immunohistochemistry. Following deparaffinization in xylene, the tissue sections were hydrated using graded ethanol $(100,95$ and $70 \%$ ). The sections were subsequently washed three times in deionized $\mathrm{H}_{2} \mathrm{O}$ for $1 \mathrm{~min}$ at room temperature, prior to being incubated in 3\% hydrogen peroxide for $10 \mathrm{~min}$, in order to block the endogenous peroxidase activity. Each section was then sequentially washed with phosphate-buffered saline (PBS) for 5 min prior to being blocked with 5\% horse serum (Gibco-Brl, Gaithersburg, MD, USA). The sections were then incubated overnight at $4^{\circ} \mathrm{C}$ with $1: 100$ dilution of primary rabbit anti-TLR4 antibody (cat. no. sc-16240; Santa Cruz Biotechnology, Inc., Santa Cruz, CA, USA). Following 3-5 min washes with PBS, the sections were treated with biotin-conjugated goat anti-rabbit secondary antibody for $2 \mathrm{~h}$ at $37^{\circ} \mathrm{C}$. The sections were then treated with an avidin biotin enzyme reagent (Wuhan Boster Biological Technology, Ltd.) for $30 \mathrm{~min}$, prior to being washed three times with PBS. The sections were subsequently stained with DAB and $\mathrm{DAB}$ enhancer, prior to staining with hematoxylin for $5 \mathrm{sec}$. Dehydration was performed using ethanol and xylene. Finally, the sections were covered with a glass coverslip and observed under an Olympus IX71 microscope.

Western blot analysis. The colon tissue samples were harvested from the BALB/c mice of each group, prior to being frozen and stored at $-80^{\circ} \mathrm{C}$ until further use. The colon tissue samples were homogenized in ice-cold radioimmunoprecipitation lysing buffer (Sigma-Aldrich) and were centrifuged at $12,000 \mathrm{x} \mathrm{g}$ for $15 \mathrm{~min}$ at $4^{\circ} \mathrm{C}$. The supernatant was subsequently collected in order to examine protein expression levels using western blot analysis. Protein concentrations were determined using a bicinchoninic acid protein assay reagent kit (Pierce Biotechnology, Inc., Rockford, IL USA). Equal amounts of supernatant protein $(40 \mu \mathrm{g})$ were separated by $10 \%$ SDS-PAGE, and transferred to PVDF membranes. The membranes were blocked with $5 \%$ skimmed dry milk in tris-buffered saline with $0.05 \%$ Tween ${ }^{\circledR} 20$ for $1 \mathrm{~h}$, and were then co-incubated overnight at $4^{\circ} \mathrm{C}$ with the following primary antibodies IL-1 $\beta$ (1:1,000; cat. no. sc-7884), IL-6 (1:1,000; cat. no. sc-1265), IL-8 (1:1,000; cat. no. sc-8427), IL-10 (1:1,000; cat. no. sc-1783), TNF- $\alpha$ (1:500; cat. no. sc-65440), TLR-4 (1:500; cat. no. BA1717), Phospho-NF-kB p65 (1:500), total NF-kB p65 (1:500) and $\beta$-actin (1:400; cat. no. BM0005). The membranes were subsequently washed with PBS supplemented with $0.05 \%$ Tween ${ }^{\circledR} 20$ and incubated for $2 \mathrm{~h}$ at room temperature with horseradish peroxidase-bound secondary antibodies (1:1,000; Santa Cruz Biotechnology, Inc.). $\beta$-actin was used as a loading control. Finally, the proteins were visualized using ECL reagents, and the intensity of the immunoreactive bands was quantified and normalized to the 


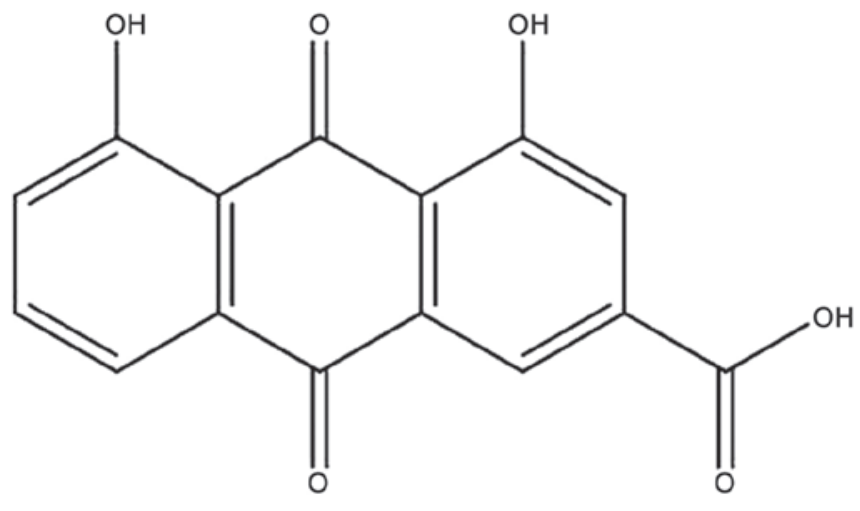

Figure 1. Chemical structure of rhein. Chemical formula, $\mathrm{C}_{15} \mathrm{H}_{8} \mathrm{O}_{6}$; molecular weight $=284.22$.

respective $\beta$-actin content using Image Pro Plus (IPP) software (Media Cybernetics, Inc., Rockville, MD, USA).

ELISA for inflammatory cytokines. Following sacrifice, blood samples of the mice were collected in heparinized tubes and centrifuged at $10,000 \mathrm{x}$ g for $10 \mathrm{~min}$ in order to obtain the plasma. The colon tissue samples of the mice in each group were subsequently harvested, weighed, and homogenized in iced saline. The samples were then centrifuged at $10,000 \mathrm{x} \mathrm{g}$ for $10 \mathrm{~min}$ in order to obtain the supernatant. The levels of inflammatory cytokines IL-1 $\beta$, IL-6, IL-8, IL-10, and TNF- $\alpha$ present in the supernatants were assayed by ELISA, according to the manufacturer's instructions. The optical densities of the samples were detected using a microplate reader (ELx800; BioTek Instruments, Inc., Winooski, VT, USA) at a wavelength of $450 \mathrm{~nm}$.

Statistical analysis. The data from at least three experiments were presented as the mean \pm standard deviation. The statistical significance of the differences between the experimental groups was analyzed using SPSS 16.0 (SPSS Inc., Chicago, IL, USA). One-way analysis of variance and post hoc Tukey tests were used to analyze the data. For all experiments, $\mathrm{P}<0.05$ was considered to indicate a statistically significant difference.

\section{Results}

Rhein extends the colon length and attenuates LPS-induced damage. Following stimulation with $20 \mathrm{mg} / \mathrm{kg}$ LPS, the length of the murine colon was markedly shortened, as compared with that of the normal mice $(\mathrm{P}<0.01)$. However, following treatment with $100 \mathrm{mg} / \mathrm{kg}$ rhein, the length of the colon was significantly increased. Notably, treatment with either $0.3 \mathrm{mg} / \mathrm{kg}$ TLR4 inhibitor TAK-242 alone or together with rhein, also increased the length of the damaged colon $(\mathrm{P}<0.05$ and $\mathrm{P}<0.01$, respectively). However, no statistically significant difference was observed between the mice treated with rhein alone, or the mice co-treated with TAK-242 (Table I).

LPS, the main endotoxin present during sepsis in the case of severe systemic inflammatory syndrome, has been shown to induce colon damage. As demonstrated in Table I, significant damage was observed in the LPS-induced mice, as compared with the normal mice. However, this damage was notably atten- uated following treatment with rhein in the presence or absence of TAK-242 $(\mathrm{P}<0.01)$. These results support the hypothesis that rhein is able to attenuate LPS-induced colon injury.

Rhein attenuates the levels of LPS-induced inflammatory cytokines. An LPS-induced inflammatory response was associated with damage to the mouse colon. ELISA was performed in order to detect the expression levels of the following inflammatory cytokines: IL-1 $\beta$, IL-6, IL- 8 , IL-10, and TNF- $\alpha$, in both the plasma and colon tissue samples. As shown in Table II, exposure to LPS markedly increased the concentration of the inflammatory cytokines IL-1 $\beta$, IL-6, IL- 8 , and TNF- $\alpha$, whereas it markedly decreased the concentration of IL-10 in the plasma and colon tissue samples, as compared with the control $(\mathrm{P}<0.01)$. Notably, the rhein-treated animals exhibited reduced expression levels of IL-1 $\beta$, IL-6, IL-8, and TNF- $\alpha$, whereas they exhibited increased expression levels of IL-10, as compared with the LPS model group $(\mathrm{P}<0.05, \mathrm{P}<0.01$, respectively). Furthermore, treatment with TLR4 inhibitor TAK-242 significantly attenuated the LPS-induced inflammatory response, increasing IL-10 expression levels and decreasing IL-1 $\beta$, IL-6, IL-8, TNF- $\alpha$ expression levels. These results were concordant with those of the western blot analysis (Fig. 2). These results suggest that the mechanism underlying the protective effects of rhein during LPS-induced intestinal toxicity is similar to that of TAK-242.

Rhein-attenuates LPS-induced TLR4 expression. In order to evaluate the effects of rhein on TLR4, immunohistochemistry and western blot analyses were performed to determine the expression levels of TLR4 in the colon. The results from the immunohistochemical imaging of the sections demonstrated the localization of TLR4 to the colon in the LPS-treated mice, which in turn resulted in increased expression levels of TLR-4 (Fig. 3A-D). However, the expression levels of TLR4 were significantly reduced following treatment with rhein, both in the presence and absence of TAK-242 $(\mathrm{P}<0.01)$. Notably, the expression levels of TLR4 in the rhein or TAK-242-treated mice were close to normal. In addition, there was no statistically significant difference between the expression levels of TLR4 in the mice co-treated with rhein and TAK-242, as compared with the mice treated with rhein alone.

Rhein reduces $N F-\kappa B$ phosphorylation via TLR4. To further investigate the effects of the rhein signaling pathway on LPS-induced intestinal toxicity during sepsis, the expression levels of both phosphorylated and total NF- $\kappa \mathrm{B}$ were analyzed. Following treatment with LPS, the expression levels of the phosphorylated NF- $\kappa \mathrm{B}$ were notably increased, as compared with the control. This upregulation was reduced following treatment with $100 \mathrm{mg} / \mathrm{kg}$ rhein $(\mathrm{P}<0.05)$. However, the expression levels of total NF- $\kappa \mathrm{B}$ were not significantly different in any of the four groups, as compared with the control group. Notably, LPS-mediated NF- $\mathrm{BB}$ phosphorylation was inhibited by treatment with TAK-242 (Fig. 4).

\section{Discussion}

Sepsis is regarded as one of the leading causes of mortality in critically ill patients exhibiting a systemic inflammatory response caused by infection. The onset of sepsis usually 
Table I. Length of murine colon and level of intestinal mucosal injury in the various mouse groups.

\begin{tabular}{lrrr}
\hline Group & $\mathrm{n}$ & $\begin{array}{c}\text { Length of } \\
\text { colon }(\mathrm{cm})\end{array}$ & $\begin{array}{c}\text { Score of } \\
\text { colon injury }\end{array}$ \\
\hline Normal & 10 & $10.25 \pm 0.78$ & 0 \\
Model & 7 & $8.15 \pm 1.14^{\mathrm{a}, \mathrm{b}}$ & $4.48 \pm 0.43^{\mathrm{a}, \mathrm{b}}$ \\
Rhein $(100 \mathrm{mg} / \mathrm{kg})$ & 10 & $9.53 \pm 0.62^{\mathrm{c}}$ & $2.40 \pm 0.77^{\mathrm{d}}$ \\
Rhein $(100 \mathrm{mg} / \mathrm{kg})+\mathrm{TAK}-242(0.3 \mathrm{mg} / \mathrm{kg})$ & 9 & $9.64 \pm 0.89^{\mathrm{c}}$ & $1.97 \pm 0.51^{\mathrm{d}}$ \\
TAK-242 $(0.3 \mathrm{mg} / \mathrm{kg})$ & 9 & $9.43 \pm 0.93^{\mathrm{d}}$ & $2.82 \pm 0.56^{\mathrm{d}}$ \\
\hline
\end{tabular}

${ }^{\mathrm{a}} \mathrm{P}<0.05,{ }^{\mathrm{b}} \mathrm{P}<0.01$, vs. the normal control group; ${ }^{\mathrm{c}} \mathrm{P}<0.05$, ${ }^{\mathrm{d}} \mathrm{P}<0.01$, vs. the model group. LPS, lipopolysaccharide.

Table II. Level of inflammatory cytokines in the plasma and colon tissue of LPS-induced septic mice.

\begin{tabular}{|c|c|c|c|c|c|}
\hline $\begin{array}{l}\text { Cytokine } \\
(\mathrm{pg} / \mathrm{ml})\end{array}$ & Normal & Model & $\begin{array}{c}\text { Rhein } \\
(100 \mathrm{mg} / \mathrm{kg})\end{array}$ & $\begin{array}{l}\text { Rhein }(100 \mathrm{mg} / \mathrm{kg})+ \\
\text { TAK-242 }(0.3 \mathrm{mg} / \mathrm{kg})\end{array}$ & $\begin{array}{c}\text { TAK-242 } \\
(0.3 \mathrm{mg} / \mathrm{kg})\end{array}$ \\
\hline \multicolumn{6}{|l|}{ Plasma } \\
\hline IL- $1 \beta$ & $38.44 \pm 5.22$ & $55.41 \pm 4.17^{b}$ & $45.38 \pm 2.14^{c}$ & $44.66 \pm 3.07^{c}$ & $46.99 \pm 4.95^{\mathrm{c}}$ \\
\hline IL-6 & $21.45 \pm 3.73$ & $38.33 \pm 4.56^{\mathrm{a}}$ & $26.82 \pm 4.26^{c}$ & $24.32 \pm 3.92^{c}$ & $26.18 \pm 4.01^{\mathrm{c}}$ \\
\hline IL-8 & $44.52 \pm 5.24$ & $62.49 \pm 8.74^{\mathrm{b}}$ & $51.77 \pm 4.28^{c}$ & $49.51 \pm 4.54^{c}$ & $49.03 \pm 2.90^{c}$ \\
\hline IL-10 & $66.54 \pm 6.83$ & $37.82 \pm 8.55^{\mathrm{b}}$ & $52.54 \pm 6.77^{\mathrm{d}}$ & $55.34 \pm 7.12^{\mathrm{d}}$ & $53.11 \pm 6.03^{\mathrm{d}}$ \\
\hline TNF- $\alpha$ & $7.73 \pm 1.56$ & $11.95 \pm 2.12^{\mathrm{a}}$ & $8.51 \pm 1.33^{c}$ & $8.22 \pm 0.94^{c}$ & $8.75 \pm 1.17^{c}$ \\
\hline \multicolumn{6}{|c|}{ Colon tissue } \\
\hline IL- $1 \beta$ & $58.78 \pm 5.86$ & $75.44 \pm 5.83^{\mathrm{a}}$ & $65.49 \pm 4.72^{c}$ & $62.37 \pm 3.36^{\mathrm{d}}$ & $66.91 \pm 4.64^{c}$ \\
\hline IL-6 & $44.27 \pm 4.31$ & $62.73 \pm 5.19^{\mathrm{b}}$ & $52.25 \pm 3.22^{c}$ & $49.67 \pm 3.67^{d}$ & $54.74 \pm 3.88^{c}$ \\
\hline IL-8 & $77.10 \pm 8.59$ & $100.42 \pm 7.66^{b}$ & $87.24 \pm 9.75^{\mathrm{d}}$ & $84.22 \pm 6.51^{\mathrm{d}}$ & $88.04 \pm 8.93^{\mathrm{d}}$ \\
\hline IL-10 & $108.44 \pm 11.43$ & $67.48 \pm 8.41^{\mathrm{b}}$ & $87.26 \pm 10.52^{\mathrm{d}}$ & $93.79 \pm 9.68^{d}$ & $83.57 \pm 8.66^{\mathrm{d}}$ \\
\hline TNF- $\alpha$ & $21.46 \pm 5.37$ & $37.27 \pm 2.53^{\mathrm{a}}$ & $28.11 \pm 3.04^{\mathrm{c}}$ & $25.18 \pm 4.74^{c}$ & $27.30 \pm 4.35^{\mathrm{c}}$ \\
\hline
\end{tabular}

${ }^{\mathrm{a}} \mathrm{P}<0.05,{ }^{\mathrm{b}} \mathrm{P}<0.01$, vs. normal control; ${ }^{\mathrm{c}} \mathrm{P}<0.05$, ${ }^{\mathrm{d}} \mathrm{P}<0.01$, vs. model. LPS, lipopolysaccharide.

A

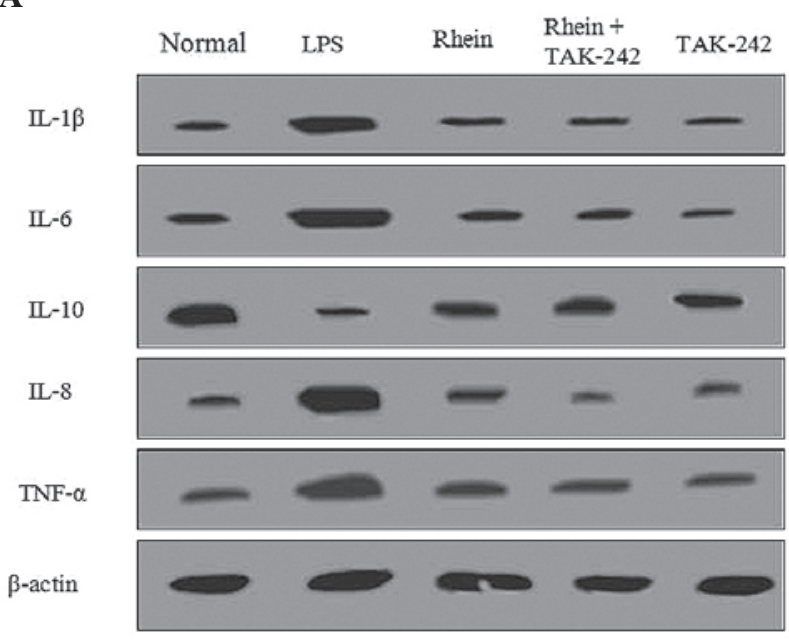

B

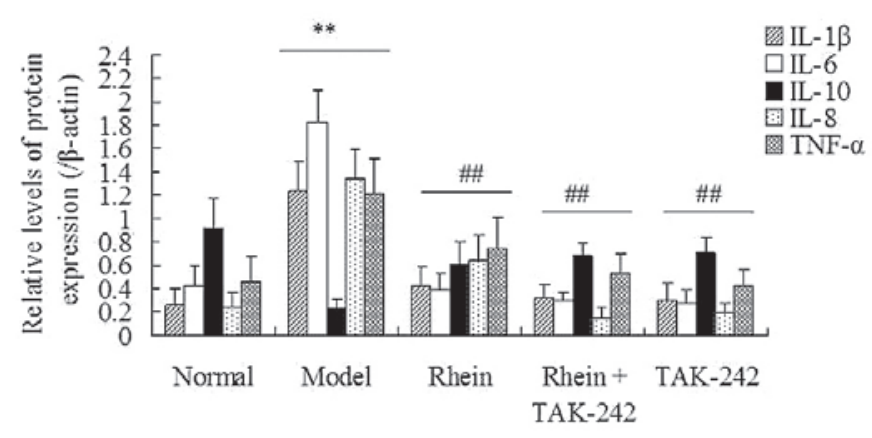

Figure 2. Effects of rhein on LPS-induced inflammatory cytokine expression as determined by western blot analysis. (A) Western blot analysis. (B) The data were normalized to $\beta$-actin. Mice were exposed to $20 \mathrm{mg} / \mathrm{kg}$ LPS prior to being treated with $100 \mathrm{mg} / \mathrm{kg}$ rhein, $0.3 \mathrm{mg} / \mathrm{kg}$ TAK-242, or both. The data are presented as the mean \pm standard deviation $(\mathrm{n}=3)$. ${ }^{* *} \mathrm{P}<0.01$, vs. the normal control group; ${ }^{* \#} \mathrm{P}<0.01$, vs. the model group. LPS, lipopolysaccharide, IL, interleukin; $\mathrm{TNF}$, tumor necrosis factor. 
A

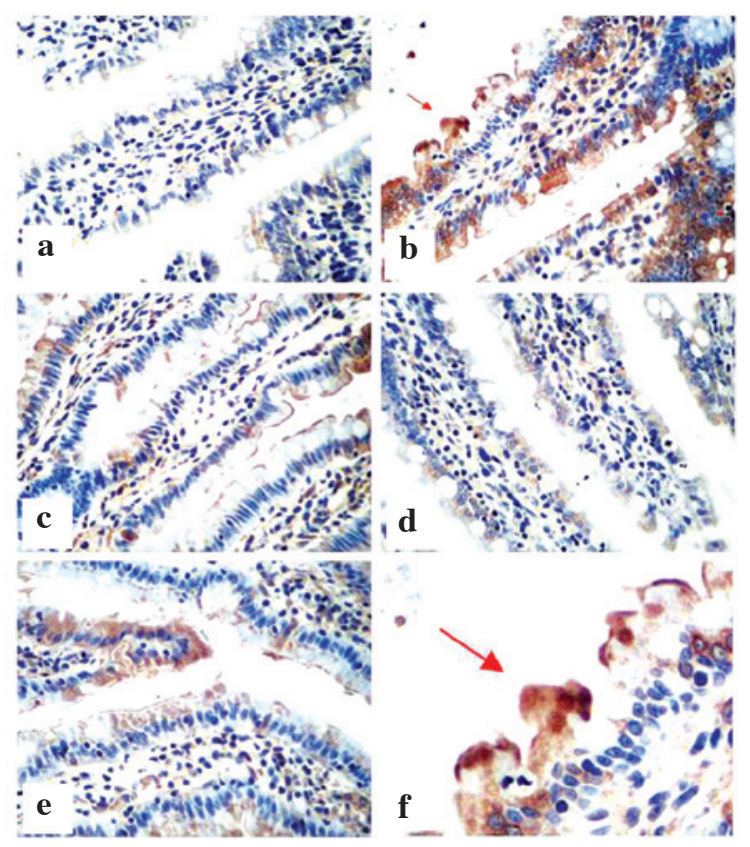

B

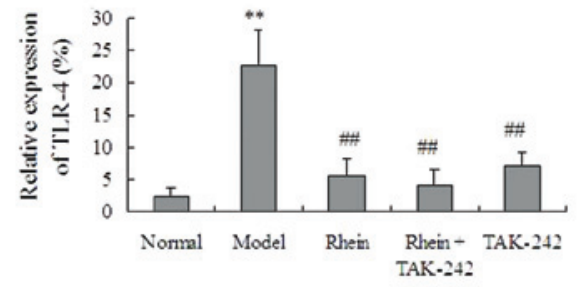

C

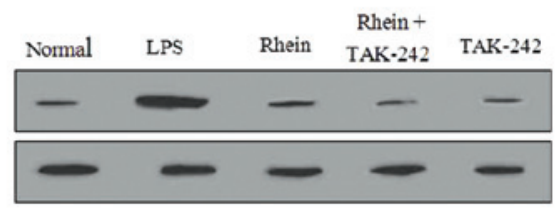

D

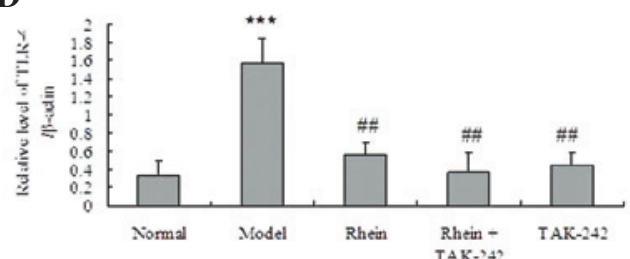

Figure 3. Effects of rhein on TLR4 expression in colon tissue. (A and B) Immunohistochemistry of TLR4 expression; (a) normal, (b) $20 \mathrm{mg} / \mathrm{kg} \mathrm{LPS}$, (c) $20 \mathrm{mg} / \mathrm{kg}$ LPS + $100 \mathrm{mg} / \mathrm{kg}$ rhein, (d) $20 \mathrm{mg} / \mathrm{kg}$ LPS $+100 \mathrm{mg} / \mathrm{kg}$ rhein $+0.3 \mathrm{mg} / \mathrm{kg}$ TAK-242, (e) $20 \mathrm{mg} / \mathrm{kg} \mathrm{LPS} \mathrm{+} 0.3 \mathrm{mg} / \mathrm{kg}$ TAK-242, (f) enlargement of (A)b image $(\mathrm{C}$ and $\mathrm{D})$ Western blotting of TLR4 expression. The data are presented as the mean \pm standard deviation $(\mathrm{n}=3) .{ }^{* *} \mathrm{P}<0.01,{ }^{* * *} \mathrm{P}<0.001$, vs. the normal control group; ${ }^{\# \#} \mathrm{P}<0.01$, vs. the model group (magnification, $\mathrm{x} 400$ ). Red arrows indicate positive expression. LPS, lipopolysaccharide; TLR, toll-like receptor.
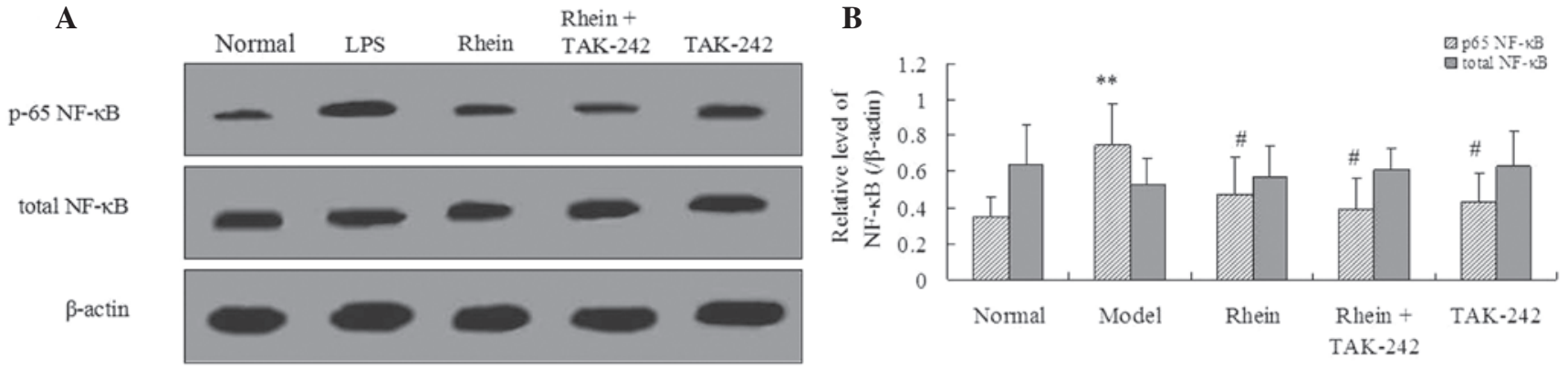

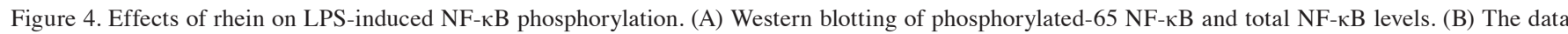
were normalized to $\beta$-actin. The data are presented as the mean \pm standard deviation $(\mathrm{n}=3) .{ }^{* *} \mathrm{P}<0.01$, vs. the normal control group; $\mathrm{P}<0.05$, vs. the model group. LPS, lipopolysaccharide; NF- $\mathrm{\kappa B}$, nuclear factor $\kappa \mathrm{B}$.

occurs following an excessive or uncontrolled inflammatory response (18). The causal relationship between intestinal damage and sepsis indicates that the intestinal tract is not only a target organ, but also the starting point of sepsis $(5,19)$. The LPS endotoxin is one of the most notable components of the bacterial cell wall, and is released into the host during bacterial growth, reproduction, lysis, or cell death (3). In addition, LPS has been suggested as a major causative factor for the onset of sepsis and septic shock caused by gram-negative bacilli (20). The accumulation of LPS activates an inflammatory response that leads to damage of the intestinal mucosal barrier, which in turn causes an increase in intestinal mucosa permeability that promotes endotoxin translocation. The present study demonstrated the protective effect of rhein, a natural constituent of Rheum rhabarbarum, on LPS-induced intestinal damage, and determined that rhein acted via the TLR4 NF- $\kappa$ B signaling pathway.

The TLR4 receptor detects foreign antigens and initiates the innate immune response. The ability of TLR4 to rapidly detect pathogens is key to the inflammatory response initiated in patients with severe sepsis (21). The LPS-induced overexpression of TLR4 is associated with changes in the levels of inflammatory mediators. Accumulating evidence has suggested that LPS-induced overactivation of the TLR4 signaling pathway leads to an increase in the production of pro-inflammatory mediators, with fatal consequences to the host (21-23). The results of the present study demonstrated that exposure to $20 \mathrm{mg} / \mathrm{kg}$ LPS increased the expression levels of TLR4 in mice colon tissue. These results support the hypothesis that LPS activates the TLR4 signaling pathway, which in 
turn regulates the inflammatory response (23). Conversely, the expression levels of TLR4 in the colon of LPS-treated mice were inhibited by rhein and TAK-242. Notably, the action of rhein on LPS-induced colon injury was similar to the action of TAK-242. Gao et al (24) previously demonstrated that rhein exhibited both pro- and anti-inflammatory activity on LPS-activated macrophages, by inhibiting the IкB kinase. However, little research has investigated the target of rhein in vivo. The results of the present study provide a novel insight into the protective effects of rhein on LPS-induced colon injury in mice.

LPS-induced inflammatory responses may impair intestinal integrity (25). During the initiation of the inflammatory septic process, changes occur in the expression levels of numerous inflammatory mediators, including an increase in the expression levels of pro-inflammatory cytokines IL-8, IL-6 and IL-1 $\beta$, and anti-inflammatory cytokine IL-10 (26). Sepsis and endotoxemia have been associated with increased production of IL-1 $\beta$, IL- 6 , IL- 8 , and TNF- $\alpha$ in the plasma and colon tissue (26). The results of the present study showed that the presence of LPS resulted in increased expression of IL-1 $\beta$, IL- 6 , IL- 8 , TNF- $\alpha$ in the plasma and colon tissue. Wang et al (27) previously demonstrated that both TNF- $\alpha$ and IL-1 $\beta$ may be involved in the regulation of gastrointestinal IL-6 production during endotoxemia in mice.

IL-10 is an early mediator and pleiotropic cytokine of the inflammatory signaling cascade that becomes elevated within a few hours of injury (28). Numerous studies have demonstrated that the anti-inflammatory cytokine IL-10 acts as a key mediator for the maintenance of gut homeostasis, by inhibiting selective elements within the inflammatory signaling cascade $(28,29)$. In immune modulator-impaired IL-10 $(\%)$ mice, LPS was shown to promote and exacerbate intestinal inflammation (30). In addition, a previous study reported that TLR-4( $\left.{ }^{\text {lps-lps- }}\right)$ mice exhibited markedly increased mRNA expression levels of IL-10 (31). In the present study, the expression levels of IL-10 in the colon tissue and plasma of mice exposed to LPS were significantly increased by rhein treatment in the presence or absence of TAK-242. These results suggested that rhein was able to attenuate LPS-induced intestinal inflammation, and emphasize the activation of IL-10 in the pathogenesis of sepsis and endotoxemia.

The NF- $\mathrm{B}$ transcription factor mediates the inflammatory response of sepsis and endotoxemia (32). LPS-induced $\mathrm{NF}-\kappa \mathrm{B}$ activation associated with TLR4 caused colon shortening and increased expression levels of IL-1 $\beta$, IL-6, and TNF- $\alpha$ in mice (33). In the present study, a marked increase in $\mathrm{NF}-\kappa \mathrm{B}$ phosphorylation occurred following LPS treatment. However, treatment with rhein significantly inhibited LPS-induced NF- $\mathrm{NB}$ phosphorylation. The inhibition of TLR4 by TAK-242 also attenuated increased NF- $\kappa$ B phosphorylation. No statistically significant difference was detected in the total $\mathrm{NF}-\kappa \mathrm{B}$ levels between the various groups. The results of the present study demonstrated that the increase in LPS-induced NF- $\mathrm{B}$ phosphorylation was markedly inhibited by treatment with rhein and TLR4 inhibitor TAK-242.

In conclusion, the present study demonstrated that rhein significantly attenuated the LPS-induced inflammatory response involved in intestinal injury during sepsis. This protection may be associated with the LPS/TLR4/NF- $\mathrm{B}$ signaling pathway. The results of the present study provide a novel insight into the mechanism underlying the protective effects of rhein on LPS-induced intestinal injury.

\section{Acknowledgements}

The present study was supported by a grant from the National Natural Science Foundation of China (grant no. 81202917).

\section{References}

1. Rajkumari N, Mathur P, Sharma S, Gupta B, Bhoi S and Misra MC: Procalcitonin as a predictor of sepsis and outcome in severe trauma patients: A prospective study. J Lab Physicians 5: 100-108, 2013.

2. Duran-Bedolla J, Montes de Oca-Sandoval MA, Saldaña-Navor V, Villalobos-Silva JA, Rodriguez MC and Rivas-Arancibia S: Sepsis, mitochondrial failure and multiple organ dysfunction. Clin Invest Med 37: E58-E69, 2014.

3. Hatakeyama N and Matsuda N: Mechanisms of inflammatory response and organ dysfunction: Organ-protective strategy by anesthetics. Curr Pharm Des: Feb 3, 2014 (Epub ahead of print).

4. Luo HM, Du MH, Lin ZL, et al: Valproic acid treatment inhibits hypoxia-inducible factor $1 \alpha$ accumulation and protects against burn-induced gut barrier dysfunction in a rodent model. PLoS One 8: e77523, 2013.

5. Fink MP: Intestinal epithelial hyperpermeability: Update on the pathogenesis of gut mucosal barrier dysfunction in critical illness. Curr Opin Crit Care 9: 143-151, 2003

6. Chatterjee N, Das S, Bose D, Banerjee S, Jha T and Saha KD: Leishmanial lipid suppresses the bacterial endotoxin-induced inflammatory response with attenuation of tissue injury in sepsis. J Leukoc Biol 96: 325-336, 2014.

7. Fatemi K, Radvar M, Rezaee A, et al: Comparison of relative TLR-2 and TLR-4 expression level of disease and healthy gingival tissue of smoking and non-smoking patients and periodontally healthy control patients. Aust Dent J 58: 315-320, 2013.

8. Musie E, Moore CC, Martin EN and Scheld WM: Toll-like receptor 4 stimulation prior to or after Streptococcus pneumoniae induced sepsis improves survival and is dependent on T-cells. PLoS One 9: e86015, 2014.

9. Yang JC, Wu SC, Rau CS, et al: Inhibition of the phosphoinositide 3-kinase pathway decreases innate resistance to lipopolysaccharide toxicity in TLR4 deficient mice. J Biomed Sci 21: 20, 2014.

10. Mascolo N, Autore G, Izzo AA, Biondi A and Capasso F: Effects of senna and its active compounds rhein and rhein-anthrone on PAF formation by rat colon. J Pharm Pharmacol 44: 693-695, 1992.

11. Raimondi F, Santoro P, Maiuri L, et al: Reactive nitrogen species modulate the effects of rhein, an active component of senna laxatives, on human epithelium in vitro. J Pediatr Gastroenterol Nutr 34: 529-534, 2002.

12. Peng SN, Zeng HH, Fu AX, Chen XW and Zhu QX: Effects of rhein on intestinal epithelial tight junction in IgA nephropathy. World J Gastroenterol 19: 4137-4145, 2013.

13. Zhang Q, Ma YM, Wang ZT and Wang CH: Differences in pharmacokinetics and anti-inflammatory effects between decoction and maceration of Sanhuang Xiexin Tang in rats and mice. Planta Med 79: 1666-1673, 2013.

14. Guo MZ, Li XS, Xu HR, Mei ZC, Shen W and Ye XF: Rhein inhibits liver fibrosis induced by carbon tetrachloride in rats. Acta Pharmacol Sin 23: 739-744, 2002.

15. Ni JQ, Ouyang Q, Lin L, et al: Role of toll-like receptor 4 on lupus lung injury and atherosclerosis in LPS-challenge ApoE\%mice. Clin Dev Immunol 2013: 476856, 2013.

16. Kim WH, Song HO, Jin CM, et al: The methanol extract of Azadirachta indica A. juss leaf protects mice against lethal endotoxemia and sepsis. Biomol Ther (Seoul) 20: 96-103, 2012.

17. Chiu CJ, McArdle AH, Brown R, Scott HJ and Gurd FN: Intestinal mucosal lesion in low-flow states. I. A morphological, hemodynamic, and metabolic reappraisal. Arch Surg 101: 478-483, 1970.

18. Cordioli RL, Cordioli E, Negrini R and Silva E: Sepsis and pregnancy: Do we know how to treat this situation? Rev Bras Ter Intensiva 25: 334-344, 2013. 
19. Van Leeuwen PA, Boermeester MA, Houdijk AP, et al: Clinical significance of translocation. Gut 35 (Suppl 1): 28-S34, 1994.

20. Cross AS, Sidberry H and Sadoff JC: The human antibody response during natural bacteremic infection with gram-negative bacilli against lipopolysaccharide core determinants. J Infect Dis 160: 225-236, 1989.

21. Piazza O, Pulcrano G, Fiori PL, et al: Toll-like receptor kinetics in septic shock patients: A preliminary study. Int J Immunopathol Pharmacol 25: 425-433, 2012.

22. Drago-Serrano ME, de la Garza-Amaya M, Luna JS and Campos-Rodríguez R: Lactoferrin-lipopolysaccharide (LPS) binding as key to antibacterial and antiendotoxic effects. Int Immunopharmacol 12: 1-9, 2012.

23. Verstak B, Stack J, Ve T, et al: The TLR signaling adaptor TRAM interacts with TRAF6 to mediate activation of the inflammatory response by TLR4. J Leukoc Biol 96: 427-436, 2014.

24. Gao Y, Chen X, Fang L, et al: Rhein exerts pro- and anti-inflammatory actions by targeting IKK $\beta$ inhibition in LPS-activated macrophages. Free Radic Biol Med 72: 104-112, 2014.

25. Sautner T, Wessely C, Riegler M, et al: Early effects of catecholamine therapy on mucosal integrity, intestinal blood flow, and oxygen metabolism in porcine endotoxin shock. Ann Surg 228: 239-248, 1998.

26. Redondo AC, Ceccon ME, Silveira-Lessa AL, et al: TLR-2 and TLR-4 expression in monocytes of newborns with late-onset sepsis. J Pediatr (Rio J) 90: 472-478, 2014.
27. Wang Q, Wang JJ, Boyce S, Fischer JE and Hasselgren PO: Endotoxemia and IL-1 beta stimulate mucosal IL-6 production in different parts of the gastrointestinal tract. J Surg Res 76: 27-31, 1998

28. Ueda Y, Kayama H, Jeon SG, et al: Commensal microbiota induce LPS hyporesponsiveness in colonic macrophages via the production of IL-10. Int Immunol 22: 953-962, 2010.

29. Paul G, Khare V and Gasche C: Inflamed gut mucosa: Downstream of interleukin-10. Eur J Clin Invest 42: 95-109, 2012.

30. Im E, Riegler FM, Pothoulakis C and Rhee SH: Elevated lipopolysaccharide in the colon evokes intestinal inflammation, aggravated in immune modulator-impaired mice. Am J Physiol Gastrointest Liver Physiol 303: G490-G497, 2012.

31. Chung YW, Choi JH, Oh TY, Eun CS and Han DS: Lactobacillus casei prevents the development of dextran sulphate sodium-induced colitis in Toll-like receptor 4 mutant mice. Clin Exp Immunol 151: 182-189, 2008.

32. Teo JD, Macary PA and Tan KS: Pleiotropic effects of Blastocystis spp. Subtypes 4 and 7 on ligand-specific toll-like receptor signaling and NF- $\kappa \mathrm{B}$ activation in a human monocyte cell line. PLoS One 9: e89036, 2014.

33. Lee JH, Lee B, Lee HS, et al: Lactobacillus suntoryeus inhibits pro-inflammatory cytokine expression and TLR-4-linked NF-kappaB activation in experimental colitis. Int J Colorectal Dis 24: 231-237, 2009. 